\title{
A Meta-analysis Study of Association Between FecB Polymorphism and Litter Size in Sheep
}

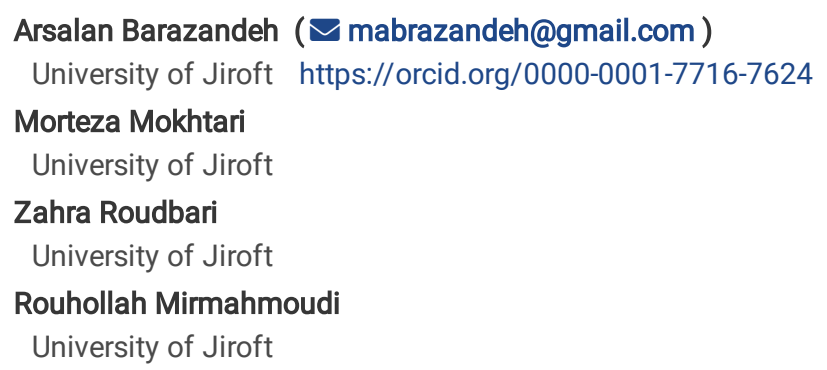




\section{Abstract}

Litter size is perhaps the main commercial trait since it has an observable effect on benefit in the sheep industry. Fecundity genes, play a vital role in expression of litter size. One of the most popular of these genes is the Booroola gene (FecB). In many past researches there was a dependency between the BMPR1B gene polymorphism and litter size of sheep. In the current study, a meta-analysis directed by coalescing outcoming of 9902 cases of 26 published research wherein various breeds of sheep to assess the influence of the FecB gene on litter size utilizing additive, recessive, dominant, and co-dominant genetic models. The random effects model was used for data analysis according to the Cochran $\mathrm{Q}$ test and $\mathrm{I}^{2}$ quantity. Under additive $(S M D=0.528)$, dominant $(S M D=0.468)$ and recessive $(S M D=0.250)$ models, the significant effect $(P<0.01)$ of FecB genotypes has been identified. Furthermore, under the co-dominant ( $S M D=-0.050, P=0.3332)$ model, the association between FecB genotypes and litter size trait had not been detected. A growth in litter size by about 0.47 lambs (Dominant model) was associated with the first copy of the FecB gene and 0.25 lambs (Recessive model) with the second copy of this gene. Consequences of the current study support the idea that BMPR1B fundamentally influenced litter size and subsequently it may be utilized for Marker-assisted selection programmers for improved genetic merit of reproductive futures and furthermore insert this gene by crossbreeding in low prolific breeds may improve reproductive characteristics.

\section{Introduction}

Sheep farming is incompetent and unprofitable due to low efficiency. One of the best ways to improve this situation is the improvement of the fecundity and fertility of sheep via selective practices (Li et al., 2021). One of the fundamental reproductive traits in sheep is litter size that is affected by many unknown factors. Because of low heritability of this trait, traditional breeding strategies have been useless to increase it rapidly (Mahdavi et al., 2014; Wang et al., 2015). Consequently, researchers hold sought to seek a number of variants of candidate genes act on litter size that should stand helpful for marker-assisted selection (MAS) and molecular genetics techniques. Findings demonstrated that a range of different genes, commonly termed fecundity (Fec) genes, play an important roleon litter size. One of the most popular of these genes is Bone morphogenetic protein receptor type IB (BMPR1B) which is famous as activin-like Kinase 6 or FecB or Booroola gene (Wilson et al. 2001, Chu et al. 2011, Plakkot et al. 2020).

Booroola gene is the member of the transforming growth factor (TGF) $\beta$ super-family, which is mapped at the FecB locus existing among the Osteopontin (OPN) and epidermal growth factor (EGF) genes on chromosome 6 including a coding sequence of 1509 bp, component of ten exons as code for 502 amino acids (Singh et al., 2020). A transition of adenine to guanine at the nucleotide site 746, result in the substitution of glutamine amino acid to arginine amino acid at location 249 (Q249R) for mutant types (Mulsant et al., 2001; Potki et al., 2020). This mutation in Fec B allele is associated with the additive effect on ovulation rate and litter size in Booroola Merino sheep (Souza et al., 2001; Davis et al., 2002; Guan, S.-R. Liu, et al., 2007; Fogarty, 2009)Considering the importance of this gene, many researchers started out to screen other prolific sheep breeds to identify it. The BMPR1B mutation has been found for example in Garole and Javanese (Davis et al., 2002; Davis, 2005), Hu and Small Tail Han (Hua and Yang, 2009), Kendrapada (Kumar et al., 2008) and Kalehkoohi (Mahdavi et al., 2014). However nearly all researches there was a dependency between the FecB gene polymorphism and litter size (Yang et al. 2010, Chu et al. 2011, Debnath and Singh 2014, Wang et al. 2018), but in some studies, this association was not significant (Hua et al., 2008; Tian et al., 2009; Hernandez H et al., 2019)A meta-analysis including random effects may clear up the heterogeneity between the studies (Dawson et al., 2016; Delphino et al., 2021a). Meta-analysis is a helpful methodology for incorporating of results revealed in various researches and to give enormous informational data to survey by pooling the consequences of these investigations. In like manner, by leading meta-analysis, there can be remuneration for a small sample size of single researches through expanding the statistical sensitivity and accuracy of assessments (Sutton et al., 2000; Hunter and Schmidt, 2004; Mahmoudi et al., 2019; Delphino et al., 2021a).

A meta-analysis of the influences of the FecB gene polymorphism on sheep litter size (Chong et al., 2019) utilized just Chinese sheep breeds, and contrasted only FecB genotypes to evaluate appropriately the relationship between litter size and FecB polymorphism. Therefore, the current study intended to do a meta-analysis of relationships of litter size and FecB polymorphism in sheep with four distinct genetic models including the additive, dominant, co-dominant and recessive.

\section{Materials And Methods}

\section{Searching strategy and screening criteria for literature review}

Criteria from the Preferred Reporting Items for Systematic Reviews and Meta-Analysis (PRISMA) checklist were used to pick qualified documents for the meta-analysis (Moher et al., 2009).

In order to locate all related research studies in distinct languages, a systematic literature search was performed for electronic databases and publications (PubMed, Science Direct, Springer, Web of Science, Google Scholar, Wiley Online Library, CNKI, Magiran and sid). The following search terms were combined to identify appropriate studies: 'BMPR1B','BMPR-1B', ' Bone morphogenetic protein receptor 1B', 'ALK6', 'activin receptor-like kinase 6', 'fecundity' ,'FecB', 'Booroola', 'Gene polymorphism', 'association', 'sheep', ' reproductive traits', 'litter size' and 'prolificacy', As well, to classify eligible studies that may not have been found in the searching processes, reference lists of the documents were thoroughly investigated. 


\section{Criteria of eligibility and method of selection}

In the present meta-analysis study, a research has been incorporated if it only matched all of the following criteria: (1) supplied allele frequencies and various genotype frequencies of the corresponding litter sizes, (2) stated sample size for each genotype of FecB, (3) assessing the association between FecB gene polymorphism and sheep litter size, (4) For each genotype, litter size least square means identified and (5) standard error/standard deviation for least square means recorded has been given. The studies have been ruled out whether they're: (i) in summary form; (ii) duplicate studies; (iii) inadequate information; or (iv) review paper.

\section{Data collection process}

To extract data file, a standard data extraction form was utilized, counting the first author name, sample size, country study, year of publication breed, frequency of genotype, least square mean and standard deviation/standard error of each genotype. When the standard deviation was not published it was determined using the following function:

$$
S D=S E \sqrt{N}
$$

where, $\mathrm{N}$ is a sample size and SE is the standard error of mean for genotypes. Based on the Cochrane Methodology (Higgins et al., 2019), pooled the least square means and standard deviations were determined as shown below:

$$
S D_{\text {pooled }}=\sqrt{\frac{\left(N_{1}-1\right) S D_{1}^{2}+\left(N_{2}-1\right) S D_{2}^{2}+\frac{N_{1} N_{2}}{N_{1}+N_{2}}\left(M_{1}^{2}+M_{2}^{2}+2 M_{1} M_{2}\right)}{N_{1}+N_{2}-1}}
$$

In which, N1 and N2 are the sample sizes, the least square mean is M1 and M2, and the standard deviations recorded for the first and second classes are SD1 and SD2, respectively.

\section{Statistical analysis}

The statistical analysis has been carried out using $R$ ( $v$ 4.1.1). To evaluate the effect size, the standardized mean difference (SMD) approach (Higgins et al., 2019) has been used by utilizing additive ("BB" in comparison with "++"), recessive ("BB" in comparison with "B+"+"++"), dominant ("BB"+"B+" in comparison with "++"), and co-dominant ("BB"+"++" in comparison with "B+") genetic models, to study the association between litter size and FecB polymorphism in sheep.

The Cochran's Q (Cochran, 1954); and I-squared statistics $\left(\mathrm{I}^{2}\right)$ (Higgins et al., 2003, 2019) were used to measure the heterogeneity among included research to ensure that all involved researches are drawn from the identical population. The fixed-effects model was used when the studies are considered homogeneous, while a random-effects model was utilized for heterogeneous studies (DerSimonian and Laird, 1986; Higgins et al., 2003). A fixed effects model assumes that the differences observed among research are caused by chance alone, while the model of random effects assumes that different studies can have significant diversity and tests variations within and between studies(Hatala et al., 2005; Chong et al., 2019). The sensitivity analysis was done to detect the stability of the overall results by deleting one research at a time. To test publication bias, first of all, to evaluate the asymmetry of the funnel plot, the improved funnel plots with the contour were inspected (Peters et al., 2008) and Egger's intercept test (Egger et al., 1997) were employed. Where a symmetrical funnel plot suggests no publication bias. In addition, Egger's test was used to quantitatively assessment of the degree of symmetry of the Funnel plots (Sterne et al., 2011). When finding signs of publication bias, use the trim and fill technique of Duval and Tweedie to correct for possible bias (Duval and Tweedie, 2000). In the funnel plot, the trim-and-fill approach tests asymmetry and imputes the number of suspected missing studies. The changed outcome can be used as a sensitivity analysis to show the degree to which the findings of this research may have been influenced by publication bias (Joober et al., 2012; Mathur and VanderWeele, 2020).

\section{Results}

\section{Study selection}

In order to provide an overview of the literature survey and research selection at different stages of the assessment process, a PRISMA flow chart was followed (Fig. 1). Surveys of the database and screening of the reference list resulted in 127 and 24 theoretically related research, respectively. Among them, 23 papers were discarded as duplicates after the first assessment. In addition, 39 papers were in the form of a summary; and thus excluded. Of the remaining 89 papers, 63 papers were denied in total for the reasons stated: (1) The association between FecB gene polymorphisms

Page $3 / 16$ 
and the litter size trait was not investigated. (2) Sufficient data such as genotype frequencies, standard deviation and appropriate mutation were not provided; and (3) Concentrated on other traits, not litter size. Finally, 26 articles with 9902 sheep were chosen to be used in the meta-analysis. There were inquiries of more than one sheep breed in six papers thus each breed was considered as a separate research. Table 1 contains the attributes of the chosen research.

\section{Heterogeneity assessment between studies}

Table 2 summarizes the results of the application of Cochran's Q heterogeneity test and I-squared statistics $\left(I^{2}\right)$ through every genetic model. Results using the Cochran $\mathrm{Q}$ test showed that inall model (Additive, Dominant, Codominant and recessive) P values were less than 0.005 . The estimated $\mathrm{I}^{2}$ was also greater than $45 \%$ for all the considered models, Therefor the random effects model was applied to study the relationship of FecB polymorphism and sheep litter size (Higgins et al., 2019).

\section{Analysis of sensitivity and assessment of publication bias}

Evidence of data distribution asymmetry was shown by visual inspection of funnel plots in additive and recessive models (Fig. 2). This was verified by a substantial Egger intercept test (Table 4). Also, in contrast, in the dominant and codominant genetic models, intercept of Egger's test (Table 4) and funnel plots (Fig. 2) showed no significant and no evidence of publication bias, respectively. The trim-and-fill method was used (Duval and Tweedie, 2000) to adjust the estimates for possible publication bias in additive and recessive models. For the additive model, nine missing studies were assigned through the trim and fill technique and the mean effect size was corrected from SMD $=0.767$ to $S M D=0.528$. Furthermore, 10 missing studies for recessive model were imputed and modified mean effect size from SMD $=0.373$ to SMD $=0.250$.

\section{Meta-analysis of the relationship of the FecB polymorphism and litter size of sheep}

Table 3 and Figs. 3 to 6 illustrate the findings for the association between the FecB gene and the interest trait using the four genetic models. Under additive $(S M D=0.528, P<0.0001)$, dominant $(S M D=0.468, P<0.0001)$ and recessive $(S M D=0.250, P=0.0011)$ models, the significant effect of FecB genotypes has been identified. Furthermore, under the co-dominant ( $S M D=-0.050, P=0.3332)$ model, the association among FecB genotypes and litter size trait had not been detected.

\section{Discussion}

The influence of single nucleotide polymorphisms in the FecB gene on sheep litter size has been an important field of study, since it is an excellent gene. In the FecB coding sequence, a missense substitution (Q249R) is associated with the Booroola phenotype of comparatively greater prolificacy. While there has been an association between polymorphism in FecB and sheep litter size in most studies, there are still some research where this association has not been identified. These contradictory findings suggest that if a meta-analysis was done, there might be a clearer sense of an SNP-litter size association, which might be a helpful tool for evaluating whether FecB gene polymorphism was correlated with sheep litter size.

A total of 9902 cases wherein various breeds of sheep have been used to assess the influence of the FecB gene on sheep litter size. The findings of the genetic models of additive, dominant and recessive have been shown to have a positive relationship between the interest of FecB gene and litter size (Figs. 3-5.). Furthermore, by using the co-dominant model, there has been no association of FecB polymorphism with sheep litter size (Fig. 6).

There had been a disparity among animals with the 'BB', 'BB' and/or 'B+' genotypes as well as those with genotypes of ' ++ ', 'B+' and/or ' ++ ' in litter size $(p<0.01)$. In addition, with using the co-dominant model for study, there was no distinction between the $B+$ genotype and 'BB and/or ++ ' genotypes $(p>0.05)$. The findings suggested that a growth in litter size by about 0.47 lambs (Dominant model) was associated with the first copy of the FecB gene and 0.25 lambs (Recessive model) with the second copy of this gene, that in several sheep breeds have been consistently excellent (Fig. 4-5). These observations are in accordance with the finding of several published pieces of research which have shown that it has a substantial impact on the litter size (Chu et al. 2011, Debnath and Singh 2014, Mahdavi et al. 2014, Chen et al. 2015). In general, the influence of the second copy of the feb gene on the Poll Dorset sheep (Jia et al., 2005), Merino sheep (Zhu et al., 2006) and Duolang sheep gene has been further increased (Wang and Maimaitiyiming, 2011). The sample size of BB genotypes for these three breeds was so small, which may be the explanation for this occurrence. Chong et al. (2019) studied the influence of FecB polymorphism on Chinese sheep litter size by meta- analysis. They indicated that each gene copy causes a growth in litter size of 0.4 to 0.5 lambs. The findings of this research were consistent with the results of their study. The results of the current meta-analysis were consistent with Fogarty (2009) conclusions that the FecB gene increases the litter size, but he stated that with the first copy of this gene the litter size increased by 0.7 . The finding of the study can be clarified in particular, assuming that the FecB gene is not the only factor that controls the litter size, it includes many other factors, such as correlative functional genes, maternal inputs and environmental effects (Davis et al., 2006; Chen et al., 2015). Also, the findings of the current meta-analysis study suggest that certain other sheep breeding molecular markers, including the BMP15, GDF9 genes and others, will also have to be assessed. 
Current meta-analysis varies in a variety of respects from the previous meta-analysis conducted by Chong et al. (2019):(i) In their research, they included only Chinese sheep breeds, but this is not the case in the present study; (ii) To perform the studies, four distinct genetic models were used, including the additive, dominant, co-dominant and recessive models, but Chong et al. contrasted only FecB genotypes to evaluate appropriately the associations between FecB polymorphism and litter size; (iii) 26 qualifying studies were included in this current study to evaluate litter size data, while the number of studies used by Chong et al. was 21; (iv) For this meta-analysis, 9902 sheep records have been used, which is higher than the numbers used with 5089 by Chong et al. Such data may be conclusive proof that the latest meta-analysis has much greater predictive strength and provides more accurate results.

In addition, the current meta-analysis has several strengths: (i) all studies published in different language in the meta-analysis literature have been used; (ii) sensitivity analysis has been carried out by eliminating one study at a time to assess the consistency of the outcomes obtained;(iii) To accurately investigate the relationship among the FecB polymorphism and sheep litter size, four distinct genetic models containing additive, dominant, co-dominant and recessive models were used; and (iv) In order to perform the meta-analysis, have pooled a big dataset with 9902 records, which may result in more reliable results than small sample sizes.

The current meta-analysis study, however, may have some restrictions: (i) moderate to high research heterogeneity was observed under the utilized genetic models; (ii) The sample sizes of several studies involved were not sufficiently large; (iii) Only the influence of genetic factors on sheep litter size has been investigated, though litter size is a complex trait. Precautions should be taken for these considerations when interpreting the findings of this meta-analysis.

In conclusion, consequences of the current review support the idea that BMPR-IB fundamentally influenced litter size and was related to litter size in sheep and subsequently it may be utilized adequately for marker-assisted selection programmers for improving genetic merit of reproductive traits and furthermore introgression of this gene by crossbreeding in low prolific breeds can improve reproductive performance in sheep breeds.

\section{Declarations}

\section{Funding}

The authors declare that no funds, grants, or other support were received during the preparation of this manuscript.

\section{Competing Interests}

The authors declare that the research was conducted in the absence of any commercial or financial relationships that could be construed as a potential conflict of interest.

\section{Author Contributions}

All authors contributed to the study conception and design. All authors contributed to Material preparation and data collection. Data Analysis was performed by A. Barazandeh. The first draft of the manuscript was written by A. Barazandeh and all authors commented on previous versions of the manuscript. All authors read and approved the final manuscript.

\section{Data Availability}

Not Applicable

\section{Ethics approval}

This is an observational study. The XYZ Research Ethics Committee has confirmed that no ethical approval is required.

\section{References}

1. Chen, X., Sun, H., Tian, S., Xiang, H., Zhou, L., Dun, W. and Zhao, X., 2015. Increasing litter size in a sheep breed by marker-assisted selection of BMPR1B A746G mutation Journal of Genetics, 94, 139-142

2. Chong, Y., Liu, G. and Jiang, X., 2019. Effect of BMPRIB gene on litter size of sheep in China: A meta-analysis Animal Reproduction Science, 210, 106175 (Elsevier)

3. Chu, M., Jia, L., Zhang, Y., Jin, M., Chen, H., Fang, L., Di, R., Cao, G., Feng, T., Tang, Q., Ma, Y. and Li, K., 2011. Polymorphisms of coding region of BMPR-IB gene and their relationship with litter size in sheep Molecular Biology Reports, 38, 4071-4076

4. Chu, M.X., Liu, Z.H., Jiao, C.L., He, Y.Q., Fang, L., Ye, S.C., Chen, G.H. and Wang, J.Y., 2007. Mutations in BMPR-IB and BMP-15 genes are associated with litter size in Small Tailed Han sheep (Ovis aries) Journal of Animal Science, 85, 598-603

5. Davis, G.H., 2005. Major genes affecting ovulation rate in sheep Genetics Selection Evolution, 37, S11-S23 (EDP Sciences) 
6. Davis, G.H., Balakrishnan, L., Ross, I.K., Wilson, T., Galloway, S.M., Lumsden, B.M., Hanrahan, J.P., Mullen, M., Mao, X.Z., Wang, G.L., Zhao, Z.S., Zeng, Y.Q., Robinson, J.J., Mavrogenis, A.P., Papachristoforou, C., Peter, C., Baumung, R., Cardyn, P., Boujenane, I., Cockett, N.E., Eythorsdottir, E., Arranz, J.J. and Notter, D.R., 2006. Investigation of the Booroola (FecB) and Inverdale (FecXI) mutations in 21 prolific breeds and strains of sheep sampled in 13 countries Animal Reproduction Science, 92, 87-96

7. Davis, G.H., Galloway, S.M., Ross, I.K., Gregan, S.M., Ward, J., Nimbkar, B. V., Ghalsasi, P.M., Nimbkar, C., Gray, G.D., Subandriyo, Inounu, I., Tiesnamurti, B., Martyniuk, E., Eythorsdottir, E., Mulsant, P., Lecerf, F., Hanrahan, J.P., Bradford, G.E. and Wilson, T., 2002. DNA tests in prolific sheep from eight countries provide new evidence on origin of the Booroola (FecB) mutation Biology of Reproduction, 66, 1869-1874

8. Dawson, D. V, Pihlstrom, B.L. and Blanchette, D.R., 2016. Understanding and evaluating meta-analysis The Journal of the American Dental Association, 147, 264-270 (Elsevier)

9. Debnath, J. and Singh, R.V., 2014. Genetic polymorphism of boorola FecB gene and its association with litter size in balangir, shahabadi and bonpala sheep breeds Indian Journal of Animal Research, 48, 307-314

10. Delphino, B., Breno, V., Fernando, L. and Pinto, B., 2021a. Meta-analysis of genetic parameters for economic traits in buffaloes Livestock Science, 251, 104614 (Elsevier B.V.)

11. Delphino, B., Breno, V., Fernando, L. and Pinto, B., 2021b. Meta-analysis of genetic parameters for economic traits in sheep Livestock Science, 247, 104477 (Elsevier B.V.)

12. DerSimonian, R. and Laird, N., 1986. Meta-analysis in clinical trials Controlled clinical trials, 7, 177-188 (Elsevier)

13. Duval, S. and Tweedie, R., 2000. Trim and fill: a simple funnel-plot-based method of testing and adjusting for publication bias in meta-analysis Biometrics, 56, 455-463 (Wiley Online Library)

14. Egger, M., Smith, G.D., Schneider, M. and Minder, C., 1997. Bias in meta-analysis detected by a simple, graphical test Bmj, 315, $629-634$ (British Medical Journal Publishing Group)

15. Fang, D., Wu, J., Xu, J., Luo, Y., Zhang, L., Wang, L., Yang, L. and Lei, Z., 2010. Research on application effect in breeding of molecular marker in sheep BMPR-IB gene. Xinjiang Agricultural Sciences, 47, 189-194 (In Chinese)

16. Fogarty, N.M., 2009. A review of the effects of the Booroola gene (FecB) on sheep production Small Ruminant Research, 85, 75-84

17. Guan, F., Liu, S.-R., Shi, G.-Q. and Yang, L.-G., 2007. Polymorphism of FecB gene in nine sheep breeds or strains and its effects on litter size, lamb growth and development Animal Reproduction Science, 99, 44-52 (Elsevier)

18. Guan, F., Liu, S.R., Shi, G.Q. and Yang, L.G., 2007. Polymorphism of FecB gene in nine sheep breeds or strains and its effects on litter size, lamb growth and development Animal Reproduction Science, 99, 44-52

19. Hatala, R., Keitz, S., Wyer, P. and Guyatt, G., 2005. Tips for learners of evidence-based medicine: 4. Assessing heterogeneity of primary studies in systematic reviews and whether to combine their results Cmaj, 172, 661-665

20. Hernandez H, D., Montes V, D. and De la Ossa V, J., 2019. Association of the FecB polymorphism with the natural prolificacy of the Colombian Hair Sheep Revista MVZ Córdoba, 25, 1-6

21. Higgins, J.P.T., Thomas, J., Chandler, J., Cumpston, M., Li, T., Page, M.J. and Welch, V.A., 2019. Cochrane handbook for systematic reviews of interventions, (John Wiley \& Sons)

22. Higgins, J.P.T., Thompson, S.G., Deeks, J.J. and Altman, D.G., 2003. Measuring inconsistency in meta-analyses Bmj, 327, 557-560 (British Medical Journal Publishing Group)

23. Hua, G.-H. and Yang, L.-G., 2009. A review of research progress of FecB gene in Chinese breeds of sheep Animal reproduction science, 116, 1-9 (Elsevier)

24. Hua, G.H., Chen, S.L., Ai, J.T. and Yang, L.G., 2008. None of polymorphism of ovine fecundity major genes FecB and FecX was tested in goat Animal Reproduction Science, 108, 279-286

25. Hunter, J.E. and Schmidt, F.L., 2004. Methods of meta-analysis: Correcting error and bias in research findings, (Sage)

26. Jia, C., Li, N., Zhao, X., Zhu, X. and Jia, Z., 2005. Association of single nucleotide polymorphisms in exon 6 region of BMPRIB gene with litter size traits in sheep Asian-Australasian Journal of Animal Sciences, 18, 1375-1378

27. Joober, R., Schmitz, N., Annable, L. and Boksa, P., 2012. Publication bias: what are the challenges and can they be overcome? Journal of psychiatry \& neuroscience: JPN, 37, 149 (Canadian Medical Association)

28. Kang, X.L., Liu, J.L., Liu, Y.Q., Wang, S.Y. and Feng, D.Z., 2017. Association between BMPR-IB polymorphism and litter size in two sheep groups. Acta Agriculturae Boreali-Occidentalis Sinica, 26, 497-502 (In Chinese)

29. Kumar, S., Mishra, A.K., Kolte, A.P., Dash, S.K. and Karim, S.A., 2008. Screening for Booroola (FecB) and Galway (FecXG) mutations in Indian sheep Small Ruminant Research, 80, 57-61

30. Li, D., Sun, W., Ni, R., Zhang, X.N., Zhang, Y.L., Chu, M.X., Zhang, Y.F., Shen, G.Z., Chen, L. and Wu, W.Z., 2012. Genetic diversity of FecB gene and association analysis of its litter size Journal of veterinary Medicine and Animal Sciences, 31, 1-5

31. Li, H., Xu, H., Akhatayeva, Z., Liu, H., Lin, C., Han, X., Lu, X., Lan, X., Zhang, Q. and Pan, C., 2021. Novel indel variations of the sheep FecB gene and their effects on litter size Gene, 767, 145176 
32. Mahdavi, M., Nanekarani, S. and Hosseini, S.D., 2014. Mutation in BMPR-IB gene is associated with litter size in Iranian Kalehkoohi sheep Animal Reproduction Science, 147, 93-98

33. Mahmoudi, P., Rashidi, A., Rostamzadeh, J. and Razmkabir, M., 2019. Association between c . 1189G > A single nucleotide polymorphism of GDF9 gene and litter size in goats: A meta-analysis Animal Reproduction Science, 209, 106140

34. Maskur, M., Tapaul, R. and Kasip, L., 2016. Genetic polymorphism of bone morphogenetic protein receptor 1B (BMPR-1B) gene and its association with litter size in Indonesian fat-tailed sheep African Journal of Biotechnology, 15, 1315-1319

35. Mathur, M.B. and VanderWeele, T.J., 2020. Sensitivity analysis for publication bias in meta-analyses Journal of the Royal Statistical Society: Series C (Applied Statistics), 69, 1091-1119 (Wiley Online Library)

36. Moher, D., Liberati, A., Tetzlaff, J., Altman, D.G. and Group, P., 2009. Preferred reporting items for systematic reviews and meta-analyses: the PRISMA statement PLoS med, 6, e1000097 (Public Library of Science)

37. Mulsant, P., Lecerf, F., Fabre, S., Schibler, L., Monget, P., Lanneluc, I., Pisselet, C., Riquet, J., Monniaux, D., Callebaut, I., Cribiu, E., Thimonier, J., Teyssier, J., Bodin, L., Cognié, Y., Chitour, N. and Elsen, J.M., 2001. Mutation in bone morphogenetic protein receptor-IB is associated with increased ovulation rate in Booroola Mérino ewes Proceedings of the National Academy of Sciences of the United States of America, 98, 51045109

38. Pan, Z.Y., Di, R., Tang, Q.Q., Jin, H.H., Chu, M.X., Huang, D.W., He, J.N., Liu, Q.Y., Hu, W.P., Wang, X.Y., Yao, Y.X., Liu, L. and Song, C.L., 2015. Tissuespecific mRNA expression profiles of GDF9, BMP15, and BMPR1B genes in prolific and non-prolific goat breeds 2015, 452-458

39. Peters, J.L., Sutton, A.J., Jones, D.R., Abrams, K.R. and Rushton, L., 2008. Contour-enhanced meta-analysis funnel plots help distinguish publication bias from other causes of asymmetry Journal of clinical epidemiology, 61, 991-996 (Elsevier)

40. Plakkot, B., Mohanan, A. and Kanakkaparambil, R., 2020. Prolificacy in small ruminants Journal of Dairy, Veterinary \& Animal Research, 9, 8590

41. Potki, P., Mirhoseini, S.Z., Afraz, F. and Vahidi, S.M.F., 2020. A profile of single nucleotide polymorphisms in fecundity genes among iranian sheep breeds by using polymerase chain reaction-restriction fragment length polymorphism (PCR-RFLP) method Iranian Journal of Applied Animal Science, 10, 265-285

42. Ren, Y.L., Shen, Z.Q., LI, M., Xiao, N., Dong, W.Y., Li, J.L. and Wang, J.J., 2011. Association of polymorphisms in the FecB gene with litter size in Wadi sheep China Animal Husbandry and Veterinary Medicine, 38, 159-162

43. Roy, J., Polley, S., De, S., Mukherjee, A., Batabyal, S., Pan, S., Brahma, B., Datta, T.K. and Goswami, S.L., 2011. Polymorphism of fecundity genes (fecb, fecx, and fecg) in the indian bonpala sheep Animal Biotechnology, 22, 151-162

44. Shao, Y., Liu, W. and Mirinisahan, K., n.d. Study on the Relationship between the Polymorphism of BMPR-IB Gene and Litter Size in Xinjiang Cele Black Sheep

45. Shi, H.C., Niu, Z.G., Bai, J., Feng, L.J., Mu, M.R.S., Yang, Q.Y., Liu, M.J. and Jia, F., 2012. Effect on litter size of Cele black sheep and genetic regularity of BMPR-IB gene mutation Chinese Journal of Animal Science., 38, 14-17

46. Singh, P., Deepak, S. and SatyendraPal, S., 2020. Absence of Polymorphism in Booroola (FecB) Gene in Indian Muzzafarnagari Sheep Breed Journal of Animal Research, 10, 30954

47. Souza, C.J.H., MacDougall, C., Campbell, B.K., McNeilly, A.S. and Baird, D.T., 2001. The Booroola (FecB) phenotype is associated with a mutation in the bone morphogenetic receptor type $1 \mathrm{~B}$ (BMPR1B) gene Journal of Endocrinology, 169, 3-8

48. Sterne, J.A.C., Sutton, A.J., Ioannidis, J.P.A., Terrin, N., Jones, D.R., Lau, J., Carpenter, J., Rücker, G., Harbord, R.M. and Schmid, C.H., 2011. Recommendations for examining and interpreting funnel plot asymmetry in meta-analyses of randomised controlled trials Bmj, 343 (British Medical Journal Publishing Group)

49. Sun, H., Dun, W., Chen, X., Tian, S. and Tan, W., 2011. Relationship between Polymorphism of BMPR-IB Gene and Litter Size and Sexual Season for Different Sheep Breeds Journal of Hunan Agricultural Sciences, 3 (in Chinese)

50. Sutton, A.J., Abrams, K.R., Jones, D.R., Jones, D.R., Sheldon, T.A. and Song, F., 2000. Methods for meta-analysis in medical research, (Wiley Chichester)

51. Tian, X., Sun, H. and Wang, Y., 2009. Genetic polymorphism of BMPR-IB gene and effect on litter size in three sheep breeds. Journal of Northwest A \& F University-Natural Science Edition, 37, 31-36 (In Chinese)

52. Wang, W., La, Y., Zhou, X., Zhang, X., Li, F. and Liu, B., 2018. The genetic polymorphisms of TGF $\beta$ superfamily genes are associated with litter size in a Chinese indigenous sheep breed (Hu sheep) Animal reproduction science, 189, 19-29

53. Wang, W., Liu, S., Li, F., Pan, X., Li, C., Zhang, X., Ma, Y., La, Y., Xi, R. and Li, T., 2015. Polymorphisms of the ovine BMPR-IB, BMP-15 and FSHR and their associations with litter size in two Chinese indigenous sheep breeds International journal of molecular sciences, 16, 11385-11397

54. Wang, X. and Maimaitiyiming, B., 2011. Studies of BMPR-IB gene as a candidate gene for prolificacy in Duolang sheep. Xinjiang Agricultural Sciences, 47, 1813-1818 (In Chinese)

55. Wilson, T., Wu, X.Y., Juengel, J.L., Ross, I.K., Lumsden, J.M., Lord, E.A., Dodds, K.G., Walling, G.A., McEwan, J.C., O’Connell, A.R., McNatty, K.P. and Montgomery, G.W., 2001. Highly prolific Booroola sheep have a mutation in the intracellular kinase domain of bone morphogenetic protein IB

Page $7 / 16$ 
receptor (ALK-6) that is expressed in both oocytes and granulosa cells Biology of Reproduction, 64, 1225-1235

56. Yang, H., Yang, Y., Liu, S., Zhong, F., Zhang, Y. and He, Q., 2010. Analysis of Single Nucleotide Polymorphism of BMPR-IB Gene in Sheep Acta Agriculturae Boreali-Occidentalis Sinica, 9 (In Chinese)

57. Yang, Y., Feng, T., Chu, M., Yun, P., Xiao, W., Xue, Z., Zhang, J. and Meng, D., 2012. FecB mutation of BMPR-IB gene and its association with litter size and growth traits in Small Tailed Han sheep Acta Agriculturae Boreali-Sinica, 27, 38-43 (In Chinese)

58. Zhu, E.Y., Shi, H.C., Wu, J., Liu, M.J., Jian, Z.J., Bai, J. and Xu, X.M., 2006. Study on bone morphogenetic protein receptor IB as a candidate gene for prolificacy in sheep Acta Agriculturae Boreali-Occidentalis Sinica, 15, 20-30 (In Chinese)

\section{Tables}

Table 1: The genetic influence of the fecb genotypes on litter size has been included in this meta-analysis in various sheep breeds. 


\begin{tabular}{|c|c|c|c|c|c|c|c|c|c|}
\hline \multirow[t]{2}{*}{ study ID } & \multirow{2}{*}{$\begin{array}{l}\text { Year of } \\
\text { publication }\end{array}$} & \multirow[t]{2}{*}{ Country } & \multirow[t]{2}{*}{ Sheep Breed } & \multicolumn{3}{|c|}{ Genotypes } & \multicolumn{3}{|l|}{ LSmeans ${ }^{*} \pm S D$} \\
\hline & & & & ++ & $\mathrm{B}+$ & BB & ++ & $\mathrm{B}+$ & BB \\
\hline \multirow{2}{*}{$\begin{array}{l}\text { (Chen et al., } \\
\text { 2015) }\end{array}$} & \multirow[t]{2}{*}{2015} & \multirow[t]{2}{*}{ China } & F2generationso & \multirow[t]{2}{*}{13} & \multirow[t]{2}{*}{14} & \multirow[t]{2}{*}{3} & \multirow[t]{2}{*}{$1.220 \pm 1.370$} & \multirow[t]{2}{*}{$1.890 \pm 2.731$} & \multirow[t]{2}{*}{$3.000 \pm 0.869$} \\
\hline & & & fHanpermutton & & & & & & \\
\hline $\begin{array}{l}\text { (Chu et al., } \\
\text { 2011) }\end{array}$ & 2011 & China & Han & 15 & 47 & 78 & $1.140 \pm 0.620$ & $2.160 \pm 0.960$ & $2.650 \pm 0.971$ \\
\hline $\begin{array}{l}\text { (Chu et al., } \\
\text { 2007) }\end{array}$ & 2007 & China & Han & 12 & 78 & 98 & $1.250 \pm 0.589$ & $2.360 \pm 1.060$ & $2.650 \pm 0.990$ \\
\hline $\begin{array}{l}\text { (Hernandez H et } \\
\text { al., 2019) }\end{array}$ & 2019 & Colombia & OPC & 66 & 75 & 26 & $1.270 \pm 0.731$ & $1.440 \pm 0.866$ & $1.490 \pm 0.510$ \\
\hline $\begin{array}{l}\text { (Debnath and } \\
\text { Singh, 2014) }\end{array}$ & 2014 & India & Shahabadi & 24 & 76 & 0 & $1.000 \pm 0.441$ & $1.179 \pm 0.523$ & $N A^{*}$ \\
\hline $\begin{array}{l}\text { (Fang et al., } \\
2010)\end{array}$ & 2010 & China & GermanMerino & 11 & 22 & 14 & $1.950 \pm 0.700$ & $2.060 \pm 0.521$ & $2.530 \pm 1.160$ \\
\hline $\begin{array}{l}\text { (Fang et al., } \\
2010)\end{array}$ & 2010 & China & Han & 7 & 35 & 26 & $2.220 \pm 0.400$ & $2.430 \pm 1.420$ & $3.110 \pm 0.872$ \\
\hline $\begin{array}{l}\text { (Fang et al., } \\
2010)\end{array}$ & 2010 & China & GermanMerinocrossHan & 10 & 48 & 27 & $1.970 \pm 0.440$ & $2.250 \pm 1.462$ & $2.830 \pm 0.779$ \\
\hline $\begin{array}{l}\text { (Guan, S. R. Liu, } \\
\text { et al., 2007) }\end{array}$ & 2007 & China & ChineseMerino & 10 & 16 & 27 & $1.230 \pm 2.154$ & $2.340 \pm 2.508$ & $2.840 \pm 3.861$ \\
\hline (Jia et al., 2005) & 2005 & China & PollDorset & 76 & 2 & 1 & $1.140 \pm 0.349$ & $1.000 \pm 0.354$ & $2.000 \pm 0.350$ \\
\hline (Jia et al., 2005) & 2005 & China & Han & 12 & 44 & 45 & $1.420 \pm 0.866$ & $1.930 \pm 0.862$ & $2.270 \pm 0.872$ \\
\hline $\begin{array}{l}\text { (Kang et al., } \\
\text { 2017) }\end{array}$ & 2017 & China & TancrossHan & 106 & 34 & 11 & $1.320 \pm 0.474$ & $1.410 \pm 0.507$ & $1.360 \pm 0.501$ \\
\hline (Li et al., 2012) & 2012 & China & Wadi & 10 & 49 & 37 & $1.880 \pm 1.078$ & $2.380 \pm 0.749$ & $2.790 \pm 0.669$ \\
\hline $\begin{array}{l}\text { (Mahdavi et al., } \\
\text { 2014) }\end{array}$ & 2014 & Iran & Kalehkoohi & 30 & 36 & 11 & $1.379 \pm 0.745$ & $1.725 \pm 0.738$ & $1.902 \pm 0.647$ \\
\hline $\begin{array}{l}\text { (Maskur et al., } \\
\text { 2016) }\end{array}$ & 2016 & Indonesia & Indonesianfat-tailed & 168 & 67 & 15 & $1.145 \pm 1.400$ & $1.455 \pm 2.079$ & $1.685 \pm 0.639$ \\
\hline $\begin{array}{l}\text { (Pan et al., } \\
2015)\end{array}$ & 2015 & China & $\mathrm{Hu}$ & 0 & 12 & 47 & NA & $2.020 \pm 1.109$ & $2.560 \pm 3.976$ \\
\hline $\begin{array}{l}\text { (Pan et al., } \\
\text { 2015) }\end{array}$ & 2015 & China & Han & 36 & 117 & 140 & $1.750 \pm 3.240$ & $2.410 \pm 4.651$ & $2.890 \pm 11.004$ \\
\hline $\begin{array}{l}\text { (Ren et al., } \\
\text { 2011) }\end{array}$ & 2011 & China & Wadi & 28 & 104 & 54 & $1.960 \pm 1.482$ & $2.490 \pm 5.415$ & $2.810 \pm 3.079$ \\
\hline $\begin{array}{l}\text { (Roy et al., } \\
2011 \text { ) }\end{array}$ & 2011 & India & Bonpala & 2 & 22 & 73 & $1.500 \pm 0.707$ & $1.640 \pm 0.582$ & $1.710 \pm 0.632$ \\
\hline $\begin{array}{l}\text { (Shao et al., } \\
\text { n.d.) }\end{array}$ & 2012 & China & ZellerBlack & 46 & 44 & 10 & $1.980 \pm 0.610$ & $2.660 \pm 1.187$ & $3.000 \pm 0.819$ \\
\hline $\begin{array}{l}\text { (Shi et al., } \\
\text { 2012) }\end{array}$ & 2012 & China & ZellerBlack & 160 & 157 & 37 & $1.610 \pm 0.898$ & $2.160 \pm 0.840$ & $2.210 \pm 0.827$ \\
\hline $\begin{array}{l}\text { (Shi et al., } \\
\text { 2012) }\end{array}$ & 2011 & China & Duolang & 479 & 82 & 3 & $1.570 \pm 1.204$ & $2.080 \pm 0.833$ & $2.000 \pm 0.639$ \\
\hline $\begin{array}{l}\text { (Sun et al., } \\
\text { 2011) }\end{array}$ & 2011 & China & Hybridized & 16 & 38 & 17 & $1.130 \pm 1.400$ & $1.530 \pm 3.822$ & $2.250 \pm 2.062$ \\
\hline $\begin{array}{l}\text { (Tian et al., } \\
2009)\end{array}$ & 2009 & China & Tan & 165 & 60 & 25 & $1.270 \pm 0.951$ & $1.350 \pm 0.643$ & $1.430 \pm 0.560$ \\
\hline $\begin{array}{l}\text { (Tian et al., } \\
\text { 2009) }\end{array}$ & 2009 & China & Han & 8 & 24 & 36 & $1.630 \pm 0.074$ & $2.290 \pm 0.470$ & $2.830 \pm 0.378$ \\
\hline $\begin{array}{l}\text { (Wang and } \\
\text { Maimaitiyiming, } \\
\text { 2011) }\end{array}$ & 2011 & China & Duolang & 277 & 95 & 2 & $1.520 \pm 1.398$ & $2.030 \pm 0.926$ & $2.990 \pm 0.651$ \\
\hline (Wang et al., & 2015 & China & $\mathrm{Hu}$ & 19 & 685 & 57 & $1.150 \pm 0.654$ & $1.740 \pm 0.680$ & $1.890 \pm 0.695$ \\
\hline
\end{tabular}

Page 9/16 
2015)

\begin{tabular}{|c|c|c|c|c|c|c|c|c|c|}
\hline $\begin{array}{l}\text { (Wang et al., } \\
\text { 2015) }\end{array}$ & 2015 & China & Han & 19 & 765 & 85 & $1.210 \pm 0.741$ & $1.780 \pm 0.719$ & $2.060 \pm 0.719$ \\
\hline $\begin{array}{l}\text { (Wang et al., } \\
2018 \text { ) }\end{array}$ & 2018 & China & $\mathrm{Hu}$ & 12 & 182 & 1827 & $1.746 \pm 0.856$ & $2.165 \pm 1.889$ & $2.459 \pm 5.514$ \\
\hline $\begin{array}{l}\text { (Yang et al., } \\
2010)\end{array}$ & 2010 & China & Merino & 230 & 177 & 35 & $1.270 \pm 0.910$ & $1.830 \pm 0.798$ & $1.870 \pm 0.887$ \\
\hline $\begin{array}{l}\text { (Yang et al., } \\
2012 \text { ) }\end{array}$ & 2012 & China & Han & 128 & 719 & 437 & $1.740 \pm 1.697$ & $2.160 \pm 4.558$ & $2.720 \pm 2.299$ \\
\hline $\begin{array}{l}\text { (Zhu et al., } \\
2006)\end{array}$ & 2006 & China & Merino & 10 & 28 & 2 & $1.600 \pm 0.569$ & $2.110 \pm 0.571$ & $3.000 \pm 0.570$ \\
\hline (Zhu et al., & 2006 & China & Han & 4 & 17 & 16 & $2.250 \pm 0.580$ & $2.760 \pm 0.569$ & $2.810 \pm 0.568$ \\
\hline
\end{tabular}
2006)

*LSmeans, the least squares mean of litter size; SD, standard deviation; NA, Not available.

Table 2: Test findings for heterogeneity of meta-analysis research

\begin{tabular}{|c|c|c|c|c|c|}
\hline \multirow{2}{*}{ Contrasts } & \multicolumn{2}{|l|}{ Q } & \multicolumn{3}{|l|}{$\mathrm{I}^{2}$} \\
\hline & Estimated & $P$ value & Estimated & Cl_Low & Cl_Up \\
\hline Additive (BB vs '++') & 119.00 & $<0.0001$ & $68.9 \%$ & $56.6 \%$ & $77.7 \%$ \\
\hline Dominant ('BB'+'B+' vs '++') & 49.77 & 0.005 & $45.8 \%$ & $15.4 \%$ & $65.2 \%$ \\
\hline Co-dominant ('BB'+'++' vs 'B+') & 103.64 & $<0.0001$ & $71.1 \%$ & $58.4 \%$ & $79.8 \%$ \\
\hline Recessive (BB vs 'B+'+'++') & 70.38 & 0.0011 & $46.0 \%$ & $21.3 \%$ & $63.0 \%$ \\
\hline
\end{tabular}

Table 3: Meta-analysis of the association of fecb polymorphism with litter size

\begin{tabular}{|llllll|}
\hline & No. breeds & SMD & \multicolumn{2}{l}{$95 \%$ Confidence Interval } & P-value \\
\cline { 4 - 5 } Contrasts & & & Lower Limit & Upper Limit & \\
& & & & \\
Additive (BB vs '++') & 29 & 0.528 & 0.2919 & 0.7635 & $<0.0001$ \\
\hline Dominant ('BB'+'B+' vs '++') & 28 & 0.468 & 0.3527 & 0.5826 & $<0.0001$ \\
\hline Co-dominant ('BB'+'++' vs 'B+') & 31 & -0.050 & -0.1539 & 0.0538 & 0.3332 \\
\hline Recessive (BB vs 'B+'+'++') & 29 & 0.250 & 0.1070 & 0.3933 & 0.0011 \\
\hline
\end{tabular}

Table 4: outcomes of using Egger's test to survey the prevalence of publication bias in meta-analyses

\begin{tabular}{|lll|}
\hline Contrasts & Intercept & $\mathrm{P}$ \\
\hline Recessive (BB vs 'B+'+'++') & 1.21 & 0.001 \\
\hline Dominant ('BB'+'B+' vs '++') & 0.36 & 0.534 \\
\hline Co-dominant ('BB'+'++' vs 'B+') & 0.22 & 0.760 \\
\hline Additive (BB vs '++') & 1.42 & 0.010 \\
\hline
\end{tabular}

\section{Figures}




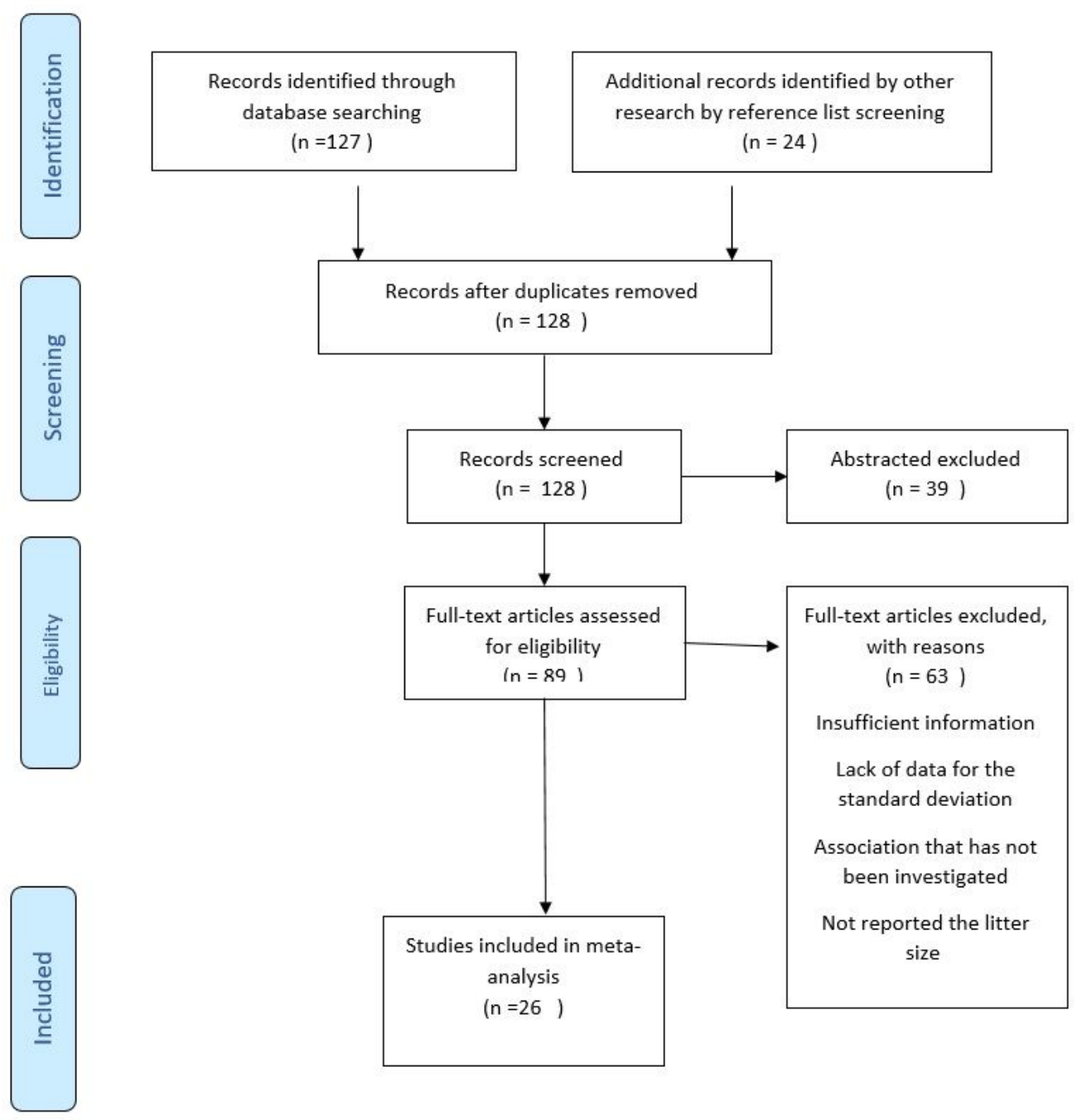

Figure 1

The PRISMA flow chart displaying incorporation and rejection rules 

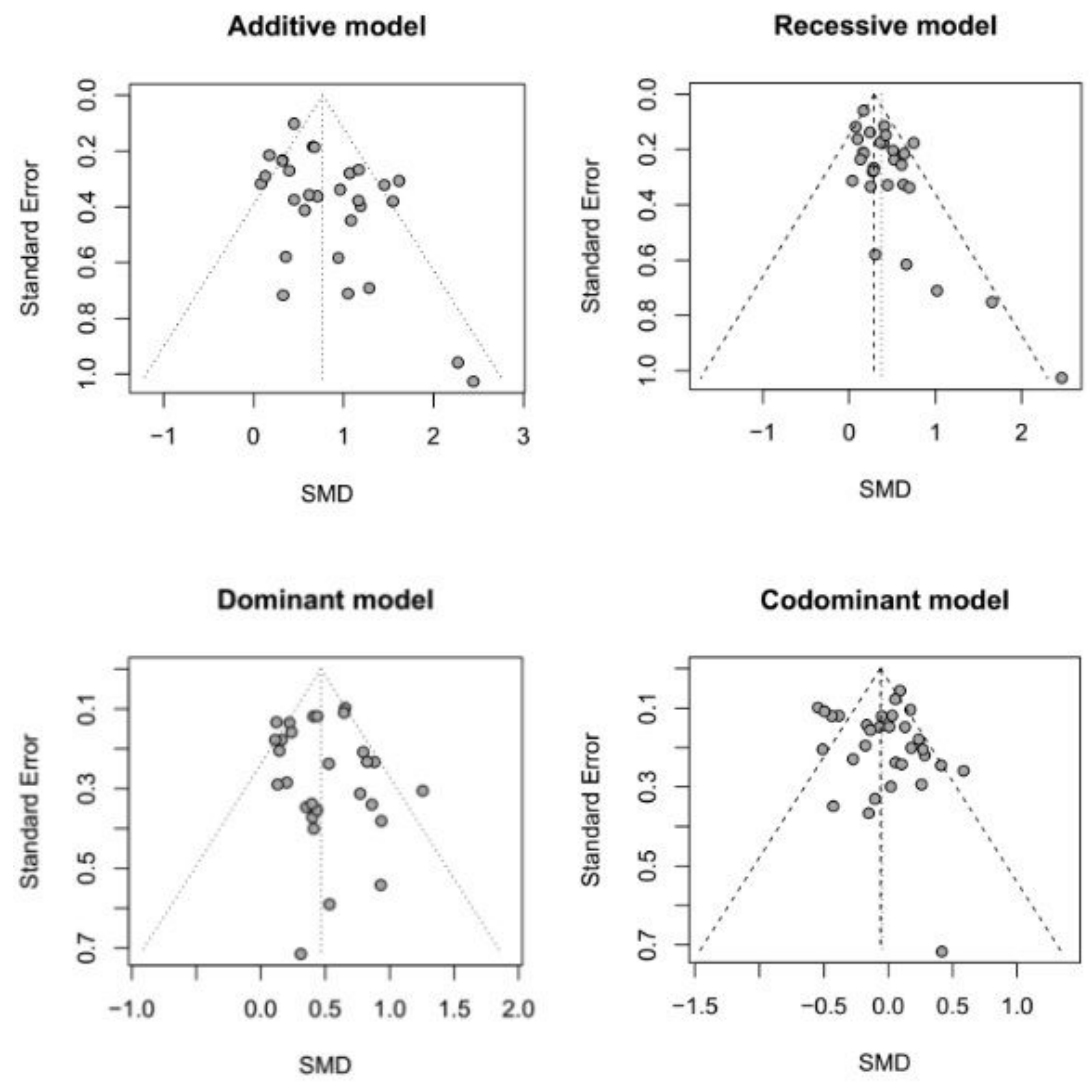

Figure 2

Funnel plot showing the relationship between the observed effect size (Standardized mean differences; solid circles) and its standard error for different genetic models in a meta-analysis 


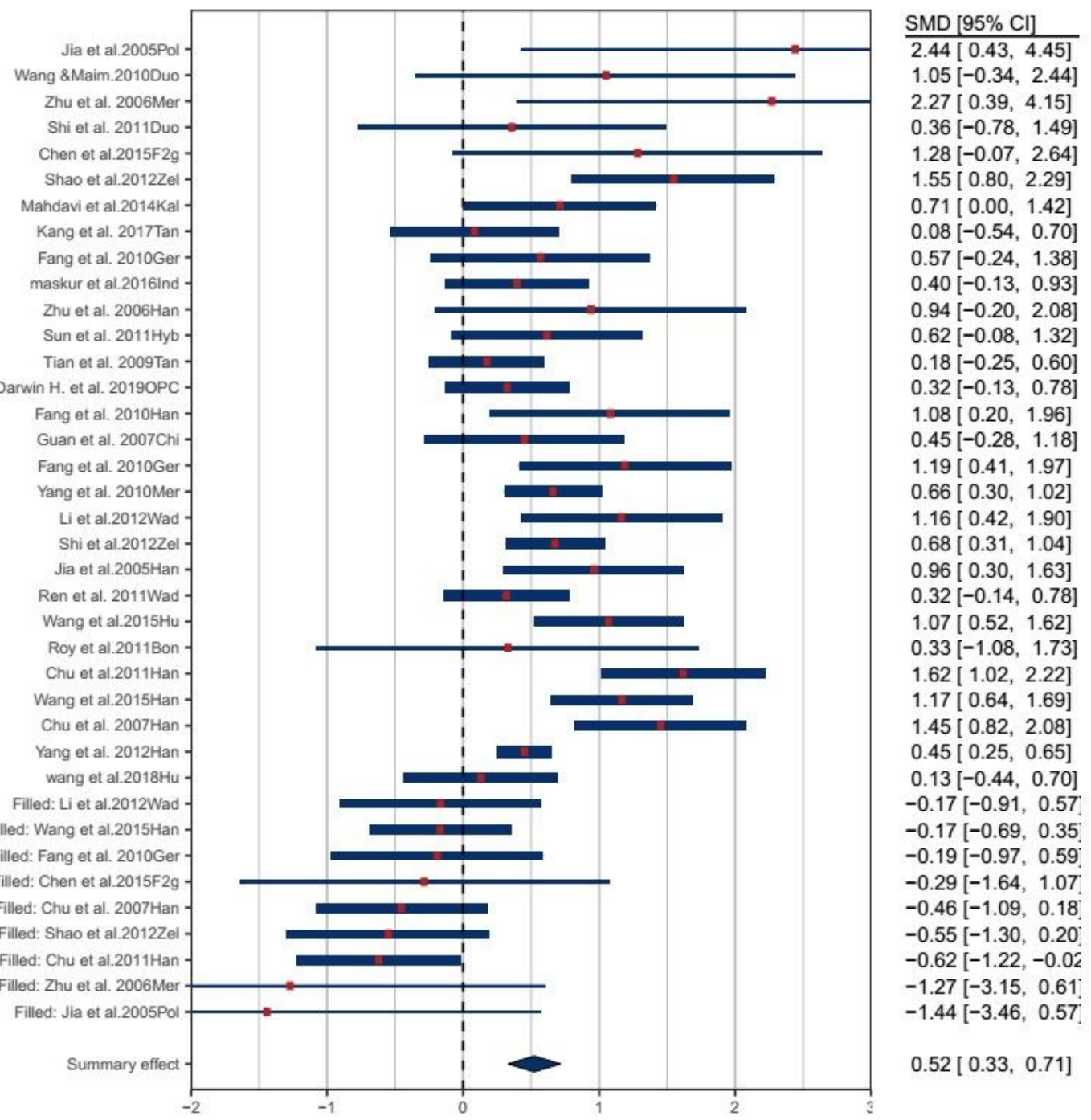

Figure 3

Forest plot for association between FecB polymorphism and litter size applying the additive model for meta-analyses the thickness and length of the blue rectangles indicate the weight and confidence interval of each study, respectively; Diamond placed at underneath of plot illustrates the summary effect 


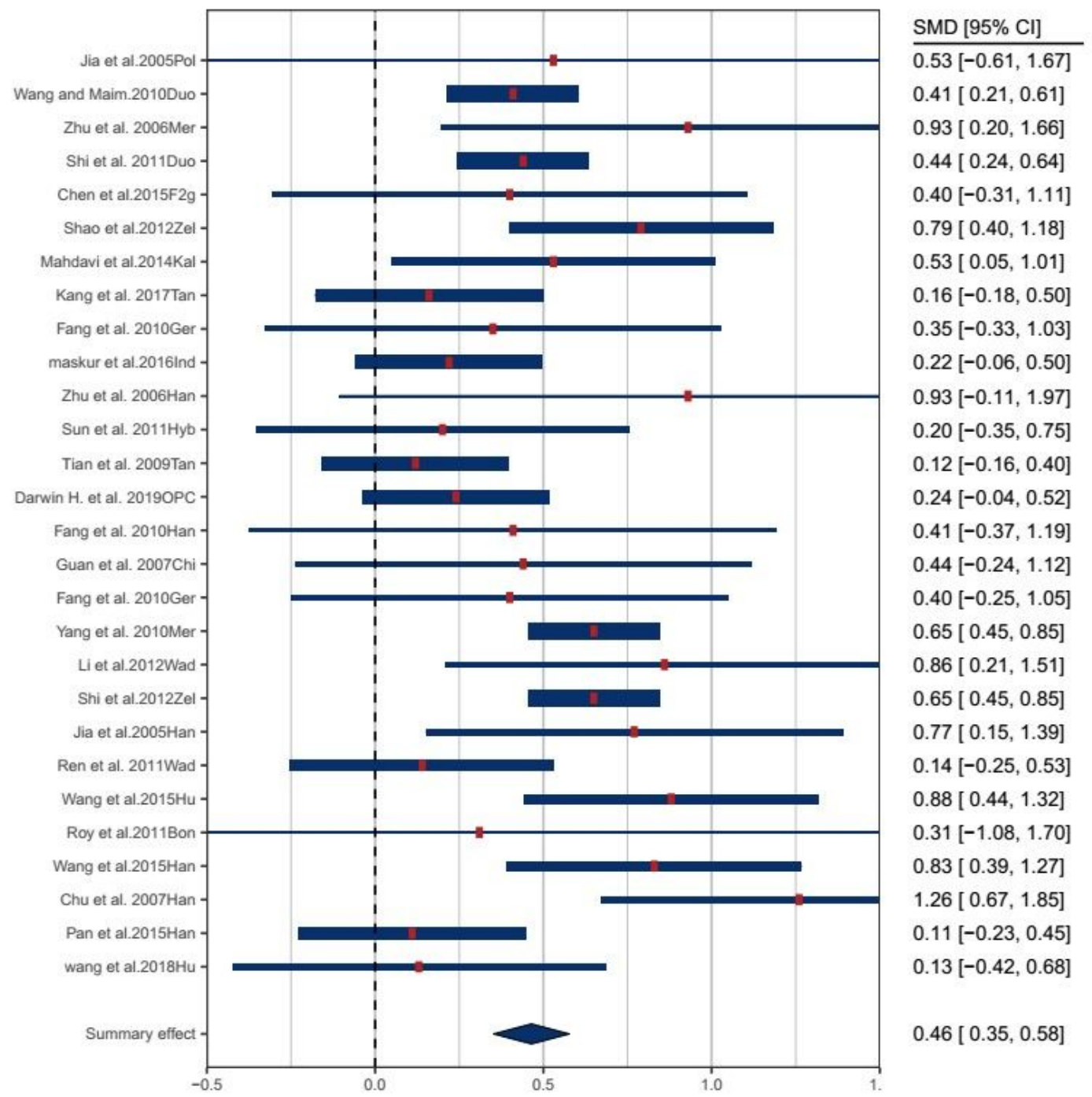

\section{Figure 4}

Forest plot for association between FecB polymorphism and litter size applying the dominant model for meta-analyses the thickness and length of the blue rectangles indicate the weight and confidence interval of each study, respectively; Diamond placed at underneath of plot illustrates the summary effect 


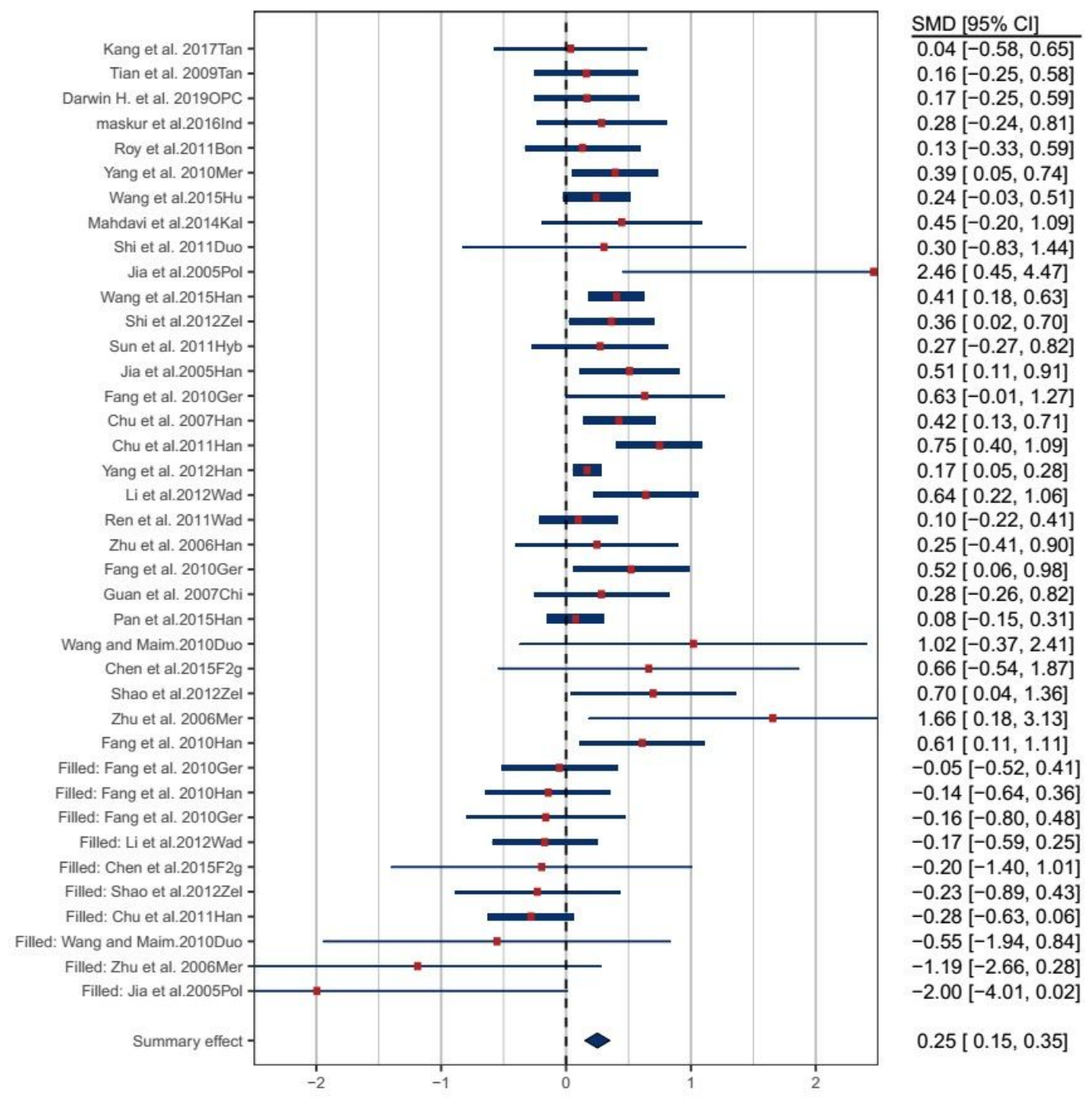

Figure 5

Forest plot for association between FecB polymorphism and litter size applying the recessive model for meta-analyses the thickness and length of the blue rectangles indicate the weight and confidence interval of each study, respectively; Diamond placed at underneath of plot illustrates the summary effect 


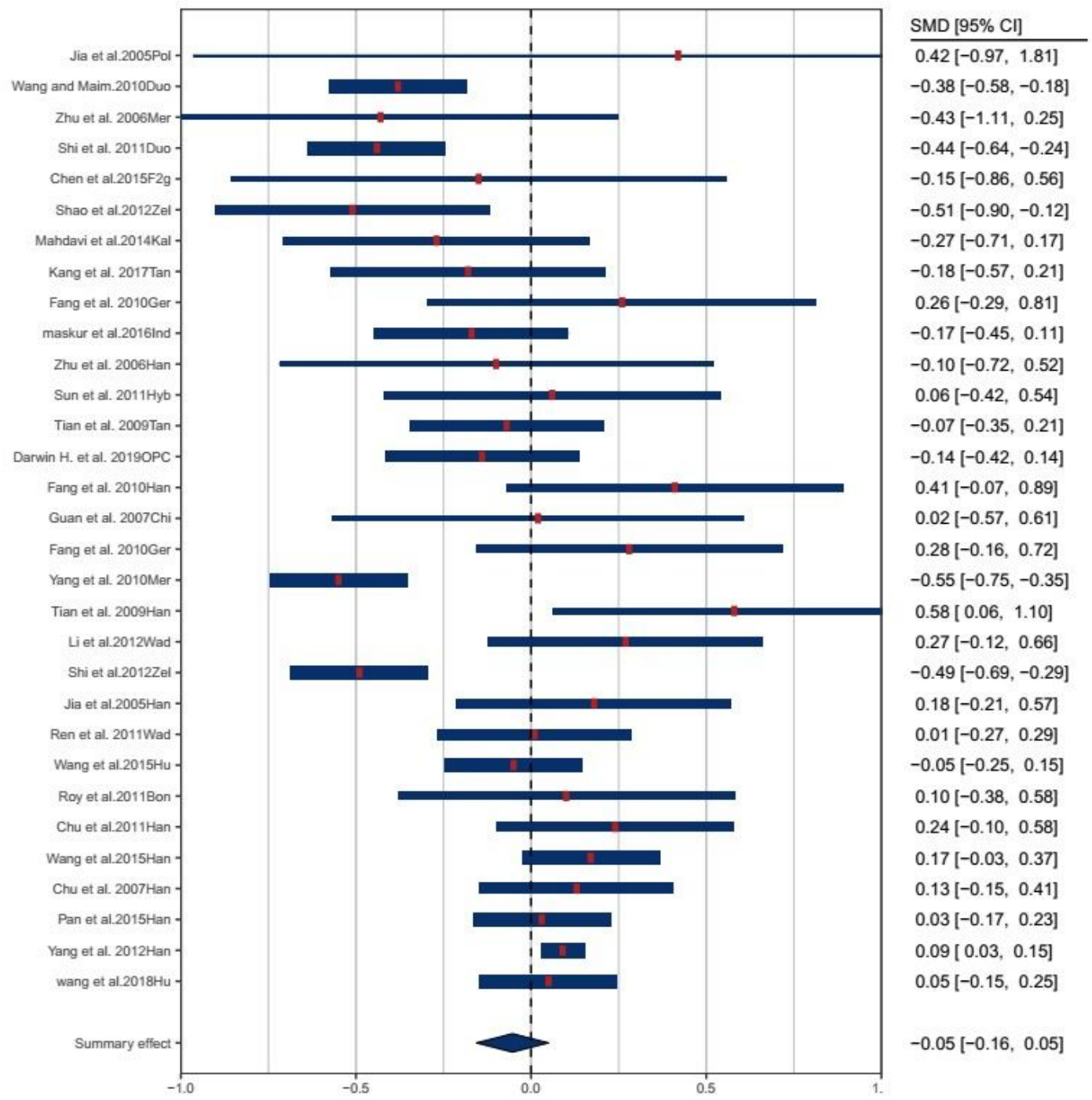

Figure 6

Forest plot for association between FecB polymorphism and litter size applying the codominant model for meta-analyses the thickness and length of the blue rectangles indicate the weight and confidence interval of each study, respectively; Diamond placed at underneath of plot illustrates the summary effect 